\title{
PERSON-CENTERED APPROACH EFFECTIVENESS IN HUMAN RESOURCE MANAGEMENT IN THE AGRICULTURE OF AZERBAIJAN
}

\author{
Shafa Guliyeva \\ Azerbaijan State University of Economics (UNEC), Baku, Azerbaijan \\ Yunus Sadigov \\ The Institute of Economics of Azerbaijan National Academy of Sciences \\ Narmin Guliyeva \\ Azerbaijan State University of Economics (UNEC), Baku, Azerbaijan \\ Leyla Isayeva \\ The Institute of Economics of Azerbaijan National Academy of Sciences
}

Shahla Aliyeva

Azerbaijan State Oil and Industry University

\begin{abstract}
The purpose of this study is to substantiate employee value (EV) and its impact on labor productivity in agriculture using the example of Azerbaijan. Using a survey of employees in agricultural enterprises, personnel values have been determined that determine the level of labor productivity in agriculture. A factor structure of EV has been determined, which has the following form: basic moral values, values of self-development and self-realization, democratic values, hedonistic values, dedication, tolerance, and power factor. The modeling by structural equations method has been used to determine the relationship between the priority of EV, the level of consistency of the system of EV, and labor productivity. The study has determined that a stimulating effect on labor productivity is provided by an increase in the priority and development of moral values, democratic values, values of self-development and self-realization, purposefulness, and tolerance among all categories of employees. The development of hedonistic values, however, has a destabilizing effect.
\end{abstract}

Keywords: agriculture, human capital, labor productivity, values, person-centered approach, Azerbaijan.

DOI: http://dx.doi.org/10.15549/jeecar.v8i2.713 


\section{INTRODUCTION}

The agricultural sector is the most important component of the national economy of Azerbaijan, playing a major role in the development of the country and providing the population with necessary consumer goods. The country's government has identified agriculture as one of four priority sectors for diversifying the national economy (International Trade Administration, 2020). Within the framework of the state program for the socio-economic development of the Republic's regions, technical re-equipment of rural areas is aimed at increasing the productivity and competitiveness of this sector (FAOLEX, 2014). The state stimulation strategy has a positive effect on the agricultural sector; according to the international humanitarian organization Oxfam, the level of self-food security in Azerbaijan is $78 \%$ (Food security as a factor in Azerbaijan's national security, 2015).

The agricultural industry in Azerbaijan is one of the largest employers in the country, which employs about $37 \%$ of the country's population and accounts for only $5 \%$ of the country's GDP (International Trade Administration, 2020). In Azerbaijan, the agricultural sector's sustainability on the economic and environmental aspect is weak. Only the social aspect can be regarded as moderate. The overall agricultural sector's sustainability is also below average. Increasing the sustainability of the economic aspect can have a significant impact weakening of the environmental aspect in the future. However, the weakness of the sustainability of agricultural sector in general creates certain inequalities between the rural regions and urban regions (Gulaliyev et.al., 2019). This indicates the low competitiveness of the industry in the national economy, caused not by the slow pace of development but by the low level of labor productivity (The State Statistical Committee of the Republic of Azerbaijan, 2021). Thus, a low level of productivity of human resources in the agricultural sector is mainly due to institutional factors and management specifics. Increasing labor productivity is the most pressing problem on which the rates of expanded reproduction in agriculture and the satisfaction of the population's needs for food depend.
The problem of increasing labor productivity itself is not new since the economic efficiency of an enterprise or industry at all stages of economic development depended on the success of solving this problem. For decades, two approaches have been clashing in economics - technocratic (Baležentis, Li \& Chen, 2020; Battisti, Belloc \& Del Gatto, 2020; Onegina et al., 2020) and person-centered (BörschSupan, Hunkler \& Weiss, 2021; Ahmadov, 2020). Representatives of the technocratic approach adhere to the point of view that technology is decisive for increasing labor productivity. Therefore, main investments must be put into the technical modernization, informatization, and digitalization of production processes (Baležentis, Li \& Chen, 2020). Supporters of the person-centered approach proceed from the fact that the main wealth of a company is its people. The main way to increase labor productivity is the optimal, creative, nonstandard use of human capital and an orientation towards the personal values of personnel (Florez \& Cortissoz, 2017; Bakas, Kostis \& Petrakis, 2020). According to supporters of the person-centered approach, the efficiency of an enterprise largely depends on how the manager treats his employees, how much he takes into account their psychological characteristics, needs, goals, and motives, and to what extent he can activate the human factor (Florez \& Cortissoz, 2017; Ismayilzade et al., 2021).

In increasing the productivity of human resources in such an economic sector as agriculture, it is not easy to give preference to any of the management approaches described above. Only the optimal combination of these can ensure the long-term success of an organization. But because the innovative and technological potential of agriculture in Azerbaijan is at a rather low level, significant investments are required for the innovative transformation of the industry (International Trade Administration, 2020), which is difficult to achieve in a crisis (Megits, Neskorodieva \& Schuster, 2020). But a technocratic approach to increasing productivity requires an appropriate quality of human capital, changes in human resources structure, and key competencies. And this, in turn, as a preparatory stage, requires the formation of a new model of human resource 
management in the industry for the rapid achievement of and adaptation to new conditions. One of the key challenges of agriculture in the 21st century is retaining, motivating, and attracting a highly skilled workforce, and increasing productivity in the industry. Therefore, within the framework of this study, the EV has been determined econometrically, which predetermines the level of labor productivity, considering the peculiarities of the development of the agricultural sector in Azerbaijan. And also, the regularities between the $\mathrm{EV}$, its priority in the process of managing labor resources, and labor productivity in agricultural enterprises are determined.

\section{LITERATURE REVIEW}

Scholars have studied labor productivity to achieve a more efficient allocation of human resources and improve quality characteristics, leading to an increase in the profitability of an organization or business (Deming et al., 2019). However, the change in labor costs (the number of work hours) does not always reflect the quality of the labor force and the efficiency of labor resources management, as it can be achieved through technological equipment and does not allow for the assessment of the economic efficiency of personnel management (Florez \& Cortissoz, 2017).

The person-centered approach, which originally arose thanks to Rogers's work in the field of individual psychotherapy and psychological counseling, was subsequently applied and spread in various fields of science, including management, (Joseph, 2019). Humancentered management empowers employees to do their best work, clearly communicates the company's goals, and shows them the path to success. Moreover, employees remain a company's most valuable asset (Wagner, 2020). It thus becomes increasingly important for businesses to treat their employees with respect and appreciation, and the efficiency of a business, enterprise, or industry depends on the satisfaction of the EV (Joseph, 2019). Most scientists mean by the EV a certain system of beliefs that prioritize a person and predetermine a conscious manifestation in relationships at work or in society (Rickaby,
Glass \& Fernie, 2020). It is personal values, as an integral part of a person, that determines where he invests his energy, resources, and time. The results of modern research indicate a direct relationship between the EV (Rickaby, Glass \& Fernie, 2020; Mazilescu et al., 2021; Bolis et al., 2021) and management (Rickaby, Glass \& Fernie, 2020; Nedelko \& Potocan, 2021; Mazilescu et al., 2021) on organizational performance by influencing labor productivity. Thus, the EV is a decisive factor in labor productivity, and effective Personnel Management is the basis of the key to its increase.

As the analysis of modern scientific literature shows, research in a person-centered approach is focused on other industries (Wagner, 2020; Nedelko \& Potocan, 2021; Bolis et al., 2021). Research on personal values in human resource management for agriculture appeared for the first time only in the early 1990s, however numerous studies are difficult to access and have been published in conferences and or short reports (Jaouani et al., 2020; Van Berkum, 2017). More recent research focuses mainly on the conceptualization of personnel management functions and the relationship between the quality of personnel management and an agricultural enterprise's economic efficiency (Inwood, 2017; Wang \& Zhao, 2019; Baležentis, Li \& Chen, 2020). The most common area of research on this topic is the impact of economic incentives, working conditions, and compensation for employees on labor productivity in agriculture (Wang \& Zhao, 2019). The conclusions drawn based on the conducted research are rather limited, which narrows the scientific potential in the development of an effective personnel policy in agriculture. Revealed patterns of personnel management in other sectors of the economy (Nedelko \& Potocan, 2021) to the specifics of the industry also cannot accurately implemented.

The law of continuous increase in labor productivity through human-centered management is common to all sectors of the national economy (Wagner, 2020). In agriculture, however, it has special forms of manifestation - this is due to the impact of natural conditions and the social structure of the industry to the level of labor productivity 
and the EV (International Trade Administration, 2020). Unlike agriculture, enterprises in other sectors of the economy are characterized by a higher level of power availability. While most of the agricultural work is done manually, labor productivity is correspondingly lower than in other sectors. In addition, the EV engaged in manual labor are shifted towards the barrier, in contrast to the representatives of mental labor (Nedelko \& Potocan, 2021).

The seasonality of labor also has many negative economic and social consequences. It leads to a loss of a significant gross output and uneven expenditure of labor and wages throughout the year. This is the main reason for the dissatisfaction of agricultural workers with the results of their labor, and it leads to staff turnover in the industry (International Trade Administration, 2020), lack of attractiveness for working youth (Van Berkum, 2017), and a low share of employees with long-term experience. Consequently, the majority of the employees in the industry are middle-aged. As a rule, a person already reaches a certain peak in social and professional development, which leads to the emergence of a sense of self-efficiency in the important areas of life and a reorientation of life (Bolis et al., 2021). The possibility of realizing long-term professional goals, adjusting career development and solving complex professional problems, and relative freedom in decisionmaking and taking the initiative are factors that increase people's tolerance to work and, consequently, their productivity (Nedelko \& Potocan, 2021).

Based on the literature review conducted within the framework of this study, the following hypotheses have been formulated:

$\mathrm{H} 1$ : the development of EV in agriculture is directly proportional to the level of labor productivity;

$\mathrm{H} 2$ : the effectiveness of personnel management in increasing labor productivity in agriculture depends on the priority of EV;

H3: the level of consistency of EV directly affects the labor productivity in agriculture.

\section{METHODOLOGY}

The survey was conducted during SeptemberNovember 2020 among enterprises operating in the agriculture, forestry, and fisheries sectors in Sheki-Zagatala, Gorno-Shirvan, Aran, GanjaGazakh, and Lankaran economic regions of Azerbaijan. The survey was aimed at identifying and defining $\mathrm{EV}$ in agriculture. The respondents were:

1) employees of enterprises;

2) heads of departments, subordinate to which are several employees;

3) top administrative and management staff.

The survey was carried out in a remote form using e-mail. Participation was voluntary and anonymous. The survey had 1004 respondents 20-24 representatives from 46 enterprises, who sent fully completed questionnaires.

The questionnaire for assessing the priority of the EV of enterprises operating in the agriculture, forestry, and fisheries sectors in Azerbaijan was based on the basic values of Schwartz (Sortheix \& Schwartz, 2017), as well as other studies (Mazilescu et al., 2021; Bolis et al., 2021). The developed questionnaire can be found at the link (Assessment of the priority of personal values, 2021). The questionnaire also contained symbols for indicators that corresponded to personal values. The respondents assessed each item of the questionnaire ( $\mathrm{Val}_{1}-\mathrm{Val}_{40}$ indicators) from the point of view of their own attitude to the value system and the value system that should be possessed by colleagues, management, the enterprise owner and partners.

The respondents' assessment of the priority of the value system was based on the theory of pairwise comparison by T. Saaty (Saaty \& Vargas, 2012). The advantage of pairwise comparison, in contrast to the scoring used in other studies such as those by Rickaby, Glass \& Fernie (2020); Nedelko \& Potocan (2021); Mazilescu et al. (2021) is that it is a more convenient way of scoring for respondents, which is confirmed by (Kudláč, Štefancová \& Majerčák, 2017). Also, this method allows for the assessment of the consistency of the given marks. According to T. Saaty (Saaty \& Vargas, 2012), pairwise comparison is carried out among all indicators that have formed a certain 
hierarchy level. In this study, there are 40 indicators (values). Pairwise comparison of the priority of all these values will lead to large amounts of data and laborious assessment for respondents. As a result, this study involved the implementation of 3 stages:

1)Splitting the initial set of values into groups, the composition of which is formed in an arbitrary order from values, regardless of the level of their development and accounting in the process of personnel management. The number of groups is not critical. The optimal number of indicators for pairwise comparison is 5-10 (Szybowski, Kułakowski \& Prusak, 2020). The value system has been divided into 8 groups ( 5 values per group). The 1st group was formed by the $\mathrm{Val}_{1}$-Val indicators, the 2nd - $\mathrm{Val}_{6}-\mathrm{Val}_{10}$, the 3rd - Val11-Val ${ }_{15}$, and so on. The respondents conducted a pairwise comparison of values within each group. The comparison was carried out on a 9point scale, with the score "1" corresponding to the equal importance of the priorities of the compared values, "3" a moderate prevalence of the priority of one value over the second, "5" - a significant advantage in priority, "7" - a significant advantage, and "9" an extreme advantage. Estimates "2", "4", "6", "7" correspond to intermediate values of priority (Saaty \& Vargas, 2012);

2)Pairwise comparison of EV, one representative from each group formed at the 1 st stage. For this, one value was selected from each group ("zero" values): $\mathrm{Val}_{1}, \mathrm{Val}_{6}, \mathrm{Val}_{11}, \mathrm{Val}_{16}, \mathrm{Val}_{21}, \mathrm{Val}_{26}, \mathrm{Val}_{31}, \mathrm{Val}_{36}$. The choice of values-representatives of groups was carried out in an arbitrary order. For these values, a pairwise comparison was carried out, similar to the 1st stage;

3)Calculation of the overall priority of the EV (formulas 1,2):

$$
b_{i}=\frac{w_{i j} \times \rho_{0 j} / w_{0 j}}{\sum_{j=1}^{n}\left(w_{i j} \times \rho_{0 j} / w_{0 j}\right)}
$$

$$
w_{i j}=\sqrt[m]{\prod_{i=1}^{m} a_{i k}} / \sum_{i=1}^{m} \sqrt[m]{\prod_{i=1}^{m} a_{i k}}
$$

Where:

$b_{i}$ - overall priority of the i-th EV;

$W_{i j}$ - the priority of the i-th EV (belonging to the $\mathrm{j}$-th group), determined at the 1st stage;

$W_{o j}$ - the priority of the 0-th EV to the j-th group, determined at the 1 st stage;

$\rho_{o j}$ - the priority of the 0 -th EV of the j-th group, determined at the 2 nd stage. The calculation of the priority of $\mathrm{EV}$ at the 2nd stage was carried out similarly to the 1 st stage ( formula 2);

$a_{i j}$ - the point estimate of the priority of the i-th $\mathrm{EV}$ relative to the $\mathrm{k}$-th value, set by the respondent;

$n$ - number of groups of EV;

$m$ - the number of EV compared at the 1st stage in the $\mathrm{j}$-th group.

The priorities calculated according to formulas (1) - (2) in the context of each respondent were used as quantitative data for statistical analysis. Using the principal components method, the factors $\left(F_{V A L}\right)$ were determined - groups of $\mathrm{EV}$ and their values for the respondents based on the indicators' $b_{i}$. When determining the optimal number of factors, the Kaiser criterion was used.

The criteria by which the adequacy of factor analysis was assessed were the sample size, which should be 2 times greater than the number of indicators (in this case, the values being assessed), and the cumulative percentage of factorization, which should be at least $80 \%$ (Menke, 2018). A sample of 1004 observations and a factorization percentage of $88.6 \%$ indicates the adequacy of the factor analysis.

To further simulate the impact of the EV on labor productivity in agricultural enterprises, the structural equations in Statistica 12.0 were used. This type of modeling is used since this toolkit provides the ability to model the relationship between explicit and latent variables.

The following indicators were used as indicators for assessing labor productivity. 
1) $L P$ is the production factor, calculated as the ratio of the cost of marketable products for 2020 to the average number of staff of the enterprise for the year;

2) $R$ is the coefficient of labor profitability costs, calculated as the company's net profit ratio for 2020 to labor costs for the corresponding period.

The $L P, R$ indices, and the uniting FLP latent variable were the endogenous variables of the model. Exogenous variables are the arithmetic mean EV factors $\left(F_{V A L}\right)$, which have been calculated in the Statistica 12.0 program for each enterprise in the context of the 3 categories of respondents: employees, heads of departments, senior administrative, and management staff. The latent variable VF was also used as an endogenous variable, which characterized the consistency of EV. This variable consisted of the coefficients of variation of the EV (each factor separately) between employees, heads of departments, top administrative, and management staff. The sample for constructing structural equations was 46 observations.

\section{RESULTS}

Based on the values of the priorities of the employees of agricultural enterprises (bi), which was calculated according to the respondents' estimates, factor analysis was carried out using the method of principal components. According to the Kaiser criterion, the optimal number of factors was 7. The list of EV that formed each of the factors was determined based on statistically significant factor loadings, the values of which exceed $|0.7|$ (see Table 1 ).

Table 1: The groups of EV in agriculture in Azerbaijan (based on the results of the survey for 2020)

\begin{tabular}{|c|c|c|c|}
\hline Factor & $\mathrm{EV}$ & $\begin{array}{l}\text { Variance of } \\
\text { the factor, \% }\end{array}$ & $\begin{array}{l}\text { Cumulative } \\
\text { variance, \% }\end{array}$ \\
\hline Basic moral values $\left(F_{\text {mor }}\right)$ & $\begin{array}{l}\mathrm{Val}_{1}, \mathrm{Val}_{2}, \mathrm{Val}_{3}, \mathrm{Val}_{6}, \mathrm{Val}_{7}, \mathrm{Val}_{8}, \mathrm{Val}_{12}, \\
\mathrm{Val}_{13}, \mathrm{Val}_{14}, \mathrm{Val}_{22}\end{array}$ & 17.9 & 17.9 \\
\hline $\begin{array}{l}\text { Self-development } \\
\text { self-realization }\left(F_{\text {real }}\right)\end{array}$ and & $\begin{array}{l}\mathrm{Val}_{19}, \mathrm{Val}_{28}, \mathrm{Val}_{29}, \mathrm{Val}_{31}, \mathrm{Val}_{34}, \mathrm{Val}_{36} \text {, } \\
\mathrm{Val}_{37}\end{array}$ & 16.1 & 34.0 \\
\hline Democratic values $\left(F_{d e m}\right)$ & $\begin{array}{l}\operatorname{Val}_{9}, \operatorname{Val}_{10}, \operatorname{Val}_{21}, \operatorname{Val}_{24}, \operatorname{Val}_{25}, \operatorname{Val}_{30}, \\
\operatorname{Val}_{32}\end{array}$ & 14.9 & 48.9 \\
\hline Hedonistic values $\left(F_{\text {hed }}\right)$ & $\mathrm{Val}_{4}, \mathrm{Val}_{5}, \mathrm{Val}_{23}, \mathrm{Val}_{26}, \mathrm{Val}_{27}$ & 12.2 & 61.1 \\
\hline Purposefulness $\left(F_{\text {purp }}\right)$ & $\operatorname{Val}_{15}, \operatorname{Val}_{33}, \mathrm{Val}_{35}, \mathrm{Val}_{38}, \mathrm{Val}_{39}$ & 11.7 & 72.8 \\
\hline Tolerance $\left(F_{t o l}\right)$ & $\operatorname{Val}_{16}, \operatorname{Val}_{17}, \operatorname{Val}_{18}, \operatorname{Val}_{20}$ & 10.8 & 83.6 \\
\hline Power $\left(F_{\text {pow }}\right)$ & $\mathrm{Val}_{11}, \mathrm{Val}_{40}$ & 5.0 & 88.6 \\
\hline
\end{tabular}

Significant factors (groups) of EV in labor productivity:

1) Basic moral values explain $17.9 \%$ of the variance. They include decency, justice, honesty, responsibility, trust, benevolence, respect for national cultural values, modesty, altruism and intelligence. These values are responsible for creating in the team a favorable atmosphere for work and a fair system of remuneration which increases labor productivity, as well as allowing for the avoidance of economic losses as a result of corruption or an unfair performance evaluation of hence, an increase in the efficiency of the enterprise.

2) The factor of self-development and selfrealization reflects the values associated with the need for personnel in development: the development of creative potential, professional competencies, communication skills, independence and determination, intellectual development, self-realization and career growth. Providing an enterprise with opportunities 
to achieve these values is an additional motivation factor, reducing staff turnover, and increasing the efficiency of the enterprise. The dispersion of this factor was $16.1 \%$.

3) The factor of democratic values is based on the absence of moral pressure in the team, threats and coercion and discrimination; the ability to listen to the opinions of colleagues, subordinates, partners; openness of colleagues, management, owners; and freedom of expression and choice of ways to achieve the set objectives. The variance of this factor was $14.9 \%$. The influence of this factor on the efficiency of the enterprise lies in the fact that by providing opportunities for the realization of these values, a working atmosphere is created without any manifestations of discrimination and, in the process of working discussion and listening to the opinion of colleagues, more effective ways to solve problems are created.

4) Hedonistic values, the dispersion of which was $12.2 \%$, create the preconditions for the effective functioning of the enterprise as a result of staff satisfaction (work, material remuneration, working conditions, psychological climate, communication in the team).

5) The purposefulness factor was formed from such values as courage, willingness to take "reasonable" risks, flexibility, mobility, discipline, rationalism in the use of their competencies and resources, and orientation towards results. Taking this factor into account in the personnel management process allows rationalizing the internal business processes at the enterprise and getting higher profits due to a focus on results and the ability to take risks. The negative impact of this factor on the efficiency of activities is possible due to the adoption of unjustified risky decisions that can lead to economic losses and excessive focus on results, neglecting other values (especially management). The variance of the factor was $11.7 \%$.

6) The tolerance factor consists of a polite attitude between team members, respect for elders, poise, and the ability to manage emotions conflict-free, which creates a favorable working atmosphere and increases labor productivity. The variance of the factor was $10.8 \%$.

7) The power factor is the most contradictory among the groups of values. On the one hand, the desire for power can motivate the employee. On the other, it can limit the democratic values of other team members due to excessive control and an authoritarian management style. The factor consists of such values as recognition from colleagues, management, partners, managing a team, and the exercise of control. The variance of the factor was $5 \%$.

Indicators of the priority of value factors for the EV of agricultural enterprises are given in Table. 2. The table shows the arithmetic mean values of the general priority of the $\mathrm{EV}$ that formed the corresponding factor in the context of categories of workers and the relative priority - the ratio of the general priority of the factor to the sum of the values of the general priorities of all factors in the context of the categories of respondents.

Table 2: Indicators of the priority of the EV of agricultural enterprises

\begin{tabular}{|l|l|l|l|}
\hline \multirow{2}{*}{ The factor of EV } & \multicolumn{3}{c|}{ Employee's categories } \\
\cline { 2 - 4 } & Employees & Heads of departments & \multicolumn{1}{c|}{ Senior management } \\
\hline \multicolumn{4}{|c|}{ Average values of the overall priority of the factor } \\
\hline$F_{\text {mor }}$ & 0.078 & 0.084 & 0.080 \\
\hline$F_{\text {real }}$ & 0.065 & 0.072 & 0.076 \\
\hline$F_{\text {dem }}$ & 0.074 & 0.076 & 0.074 \\
\hline$F_{\text {hed }}$ & 0.076 & 0.071 & 0.079 \\
\hline
\end{tabular}




\begin{tabular}{|l|l|l|l|}
\hline$F_{\text {purp }}$ & 0.061 & 0.068 & 0.071 \\
\hline$F_{\text {tol }}$ & 0.075 & 0.083 & 0.079 \\
\hline$F_{\text {pow }}$ & 0.021 & 0.023 & 0.048 \\
\hline \multicolumn{4}{|l|}{ Relative priority of the Factor, \% } \\
\hline$F_{\text {mor }}$ & 17.33 & 17.61 & 15.78 \\
\hline$F_{\text {real }}$ & 14.44 & 15.09 & 14.99 \\
\hline$F_{\text {dem }}$ & 16.44 & 15.93 & 14.60 \\
\hline$F_{\text {hed }}$ & 16.89 & 14.88 & 15.58 \\
\hline$F_{\text {purp }}$ & 13.56 & 14.26 & 14.00 \\
\hline$F_{\text {tol }}$ & 16.67 & 17.40 & 15.58 \\
\hline$F_{\text {pow }}$ & 4.67 & 4.82 & 9.47 \\
\hline
\end{tabular}

Indicators of the relative priority of factors indicate that for all categories of employees, basic moral values (15.78-17.61\%), tolerance (15.58-17.40\%), hedonistic values (14.88$16.89 \%$ ) have the highest priority. For employees and department leaders, basic moral values and tolerance are more important than for senior management. The next priority values for employees and heads of departments are democratic (relative priority $16.44 \%$ and $15.93 \%$, respectively). For senior administrative and management staff, the importance of democratic values was estimated at $14.60 \%$. Compared to democratic values for this category of employees, self-development and selfrealization are more important (value relative to priority $14.99 \%$ ). The priority of this factor for employees was $14.44 \%$, and $15.09 \%$ for heads of departments.

The relative priority for the purposefulness factor was $13.56 \%$ for employees, $14.26 \%$ for heads of departments, and $14 \%$ for top senior management. The least important EV of enterprises is power, the priority of which among the system of personal values increases with the growth of the position. The value of the relative priority of the power factor for employees was $4.67 \%$, for heads of departments $4.82 \%$, and for senior management $9.47 \%$.

Determining EV is a priority for the agricultural industry. For an empirical assessment of the relationship between the values of personnel and labor productivity in the industry, a conceptual model of influence has been developed (Fig. 1).

The simulation results determined that a statistically significant effect on the labor productivity of agricultural enterprises is exerted by the level of priority of these groups of EV: basic moral values; democratic; selfdevelopment and self-realization; tolerance; purposefulness; and hedonistic. The influence of the power factor is statistically insignificant at a significance level of $p=0.05$. The model of the influence of the priority EV on labor productivity is as follows:

$F_{L P}=0.36 \times F_{\text {mor }}+0.21 \times F_{\text {real }}+0.44 \times F_{\text {dem }}-$

$0.29 \times F_{\text {hed }}+0.21 \times F_{\text {purp }}+0.39 \times F_{\text {tol }}-1.38 \times V_{F}$ +0.05 ,

Where:

$F_{L P}$ is the value of the labor productivity factor;

$F_{m o r}$ is the priority value of basic moral values;

$F_{\text {real }}$ is the priority value of values of selfdevelopment and self-realization;

$F_{\text {dem }}$ is the priority value of democratic values;

$F_{\text {hed }}$ is the priority value of hedonistic values;

$F_{\text {purp }}$ is the priority value of purposefulness;

$F_{t o l}$ is the priority value of tolerance;

$V_{F}$ is the value of variability in the priority ratings of $\mathrm{EV}$.

According to the econometric model, a stimulating effect on labor productivity in agriculture is exerted by the orientation of 
human resource management towards these EVs: the moral values of employees, democratic, self-development and self-realization, dedication, and tolerance. The growing priority of hedonistic values and the orientation towards them in personnel management has a destabilizing effect on the efficiency of the enterprise.
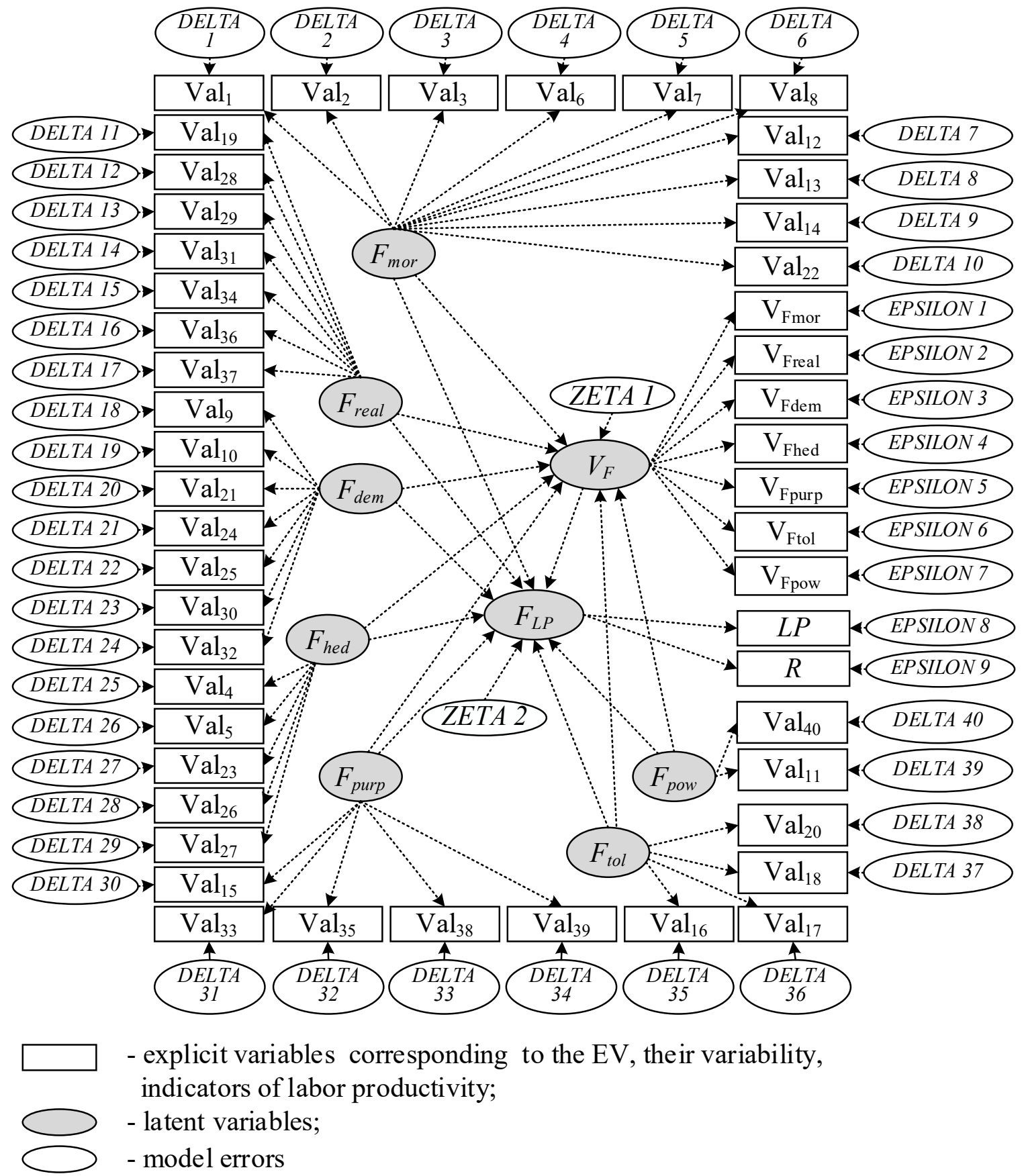

Fig. 1: Conceptual model of the interaction of EV and labor productivity in agriculture

An increase in the priority of tolerance in the EV (expressed through an increase in the corresponding factor) by $1 \%$ can increase labor productivity by $0.97 \%$. Developing basic moral values by $1 \%$ and focusing on them in the process of personnel management can increase productivity by $0.91 \%$. Increasing the priority of the values of self-development and self- 
realization by $1 \%$ can increase productivity by $0.88 \%$. And improving development of purposefulness by $1 \%$ can raise productivity by $0.80 \%$. An increase in the priority of tolerance in the EV (expressed through an increase in the corresponding factor) by $1 \%$ can increase labor productivity by $0.97 \%$. Developing basic moral values by $1 \%$ and focusing on them in the process of personnel management can increase productivity by $0.91 \%$. Increasing the priority of the values of self-development and selfrealization by $1 \%$ can increase productivity by $0.88 \%$. And improving development of purposefulness by $1 \%$ can increase productivity by $0.80 \%$. An increase in the priority indicator of hedonic values by $1 \%$ and an orientation towards them in the personnel management process leads to a decrease in labor productivity by $0.86 \%$.

The variability in assessing the priority of EV depending on the category of employees also has a statistically significant effect on labor productivity in agriculture.

Analyzing the structure of the factor of the variability of $\mathrm{EV}\left(V_{F}\right)$ concluded that an increase in variability in individual values (except power) leads to a decrease in labor productivity. The nature of the influence of the $V_{F}$ indicator on the labor productivity of enterprises is identical with the indicators $V_{\text {Fmor }}$ (variability in assessments of the priority of basic moral values), $V_{\text {Freal }}$ (variability in assessments of the priority of values of self-development and selfrealization), $V_{\text {Fdem }}$ (variability in assessments of the priority of democratic values), $V_{\text {Fhed }}$ (variability in assessments priority of hedonistic values), $V_{\text {Fpurp }}$ (variability in assessments of the priority of purposefulness), $\mathrm{VF}_{\text {tol }}$ (variability in assessments of the priority of tolerance). The inverse effect is exerted by the indicator of variability in the assessments of the priority of the power factor.

The indicators evidence the statistical significance of the constructed model of the influence of the EV on labor productivity in agriculture:

1) ICSF Criterion and ICS Criterion, whose values are close to 0 (ICSF Criterion $=2.1 \times 10^{-8}$, ICS Criterion $\left.=8.8 \times 10^{-6}\right)$;

2) Maximum Residual Cosine $\rightarrow 0$ (Maximum Residual Cosine $=6.7 \times 10^{-5}$ );
3) T-Statistic for independent variables. The empirical T-Statistic values in modulus exceed the tabular values at the significance level $\mathrm{p}=0.05$.

\section{DISCUSSION AND CONCLUSION}

The obtained results of scientific research have testified to a directly proportional relationship between the EV and the level of labor productivity in agriculture. Also, the results obtained made it possible to substantiate the influence of the dominant EV on labor productivity and partially accept the hypothesis that there is a direct relationship between the level of consistency of EV between employees representatives of different management levels and indicators of labor productivity. This hypothesis has not been confirmed for the variability of the priority of the power factor and its influence on changes in the level of labor productivity. According to the constructed models, an inverse relationship is observed between the indicators of the values of the factors and the indicator of the variability of priority assessments: the development of factors helps to reduce their variability. But this relationship is statistically insignificant at a significance level of $p=0.1$, which does not allow us to conclude that there is an indirect (through the factor variability indicator) influence of the priority of the EV on labor productivity in agriculture. The indicator of the variability of the priority of the $\mathrm{EV}$ is an independent variable that has a significant impact on labor productivity.

The study framework determined that the development of EV has a directly proportional effect on labor productivity in the country's agriculture (except power).

According to the econometric model, a stimulating effect on labor productivity in agriculture is exerted by the orientation of human resource management towards the following EVs: the moral values of employees; democratic; self-development and selfrealization; dedication; and tolerance. The desire for improvement and development, achievement of the set goals (both personal and corporate), freedom of expression of one's own opinion, and the absence of total control with a high level of development of moral values and 
tolerance in the team leads to an increase in labor productivity. With an emphasis on this system of priority for EVs, symbiosis in the middle of the enterprise is the most effective and satisfactory for workers, heads of departments, top administrative and managerial personnel, and owners (by maximizing economic efficiency). The growth of priority and the development of hedonistic values have a destabilizing effect on the efficiency of the enterprise. The desire to enjoy life can creep through such destructive factors as the desire to get rich at the company's expense while neglecting moral values and an unwillingness to take risks due to an unwillingness to leave one's comfort zone, which negatively affects labor productivity.

The calculated indicator of the elasticity of labor opposition to the variability of assessments of the priority of EV was (-1.97\%). This is higher than the elasticity of labor productivity from other factors and means that the decisive role in increasing labor productivity is played not by the priority of the EV but by its coherence. A high level of consistency can partially compensate for the low level of development of moral values, democratic values, and values of self-development and selfrealization, dedication, and tolerance.

This aspect should be considered within the framework of improving the efficiency of the personnel management system of agriculture in Azerbaijan. It will increase labor productivity and, ultimately, ensure an increase in its competitiveness both within the country and internationally.

The results correlate with studies such as Rickaby, Glass \& Fernie (2020); Nedelko \& Potocan (2021); Mazilescu et al. (2021); and Bolis et al., (2021) on the significant impact of the $\mathrm{EV}$ on labor productivity. But the uniqueness of the results obtained in this study, in contrast to Rickaby, Glass \& Fernie (2020); Nedelko \& Potocan (2021) and Bolis et al. (2021), lies in the substantiation, considering the characteristics of agriculture, of the impact on labor productivity not only of the priorities of EV but also their consistency between all structural units of agricultural enterprises.

The study carried out an empirical assessment of the impact of the EV on labor productivity in agriculture using the example of Azerbaijan, which as a result does not allow their practical implementation into a person-centric approach to human resource management in other sectors and the conditions of the industry in other countries. In addition, the scientific results were obtained without considering the time lag - the time interval between changes in the system of priority EV and the response to these labor productivity indicators. But given the seasonal nature of the agricultural industry, these aspects are of fundamental importance for improving the efficiency of human resource management. We will investigate them in future work.

\section{REFERENCES}

Ahmadov, D. (2020). Science, Technology, Engineering, and Math (STEM) effect on GDP in EU countries: Labor force perspective. Journal of Eastern European and Central Asian Research, 71), 114-121. https://doi.org/10.15549/jeecar.v7i1.236.

Assessment of the priority of personal values. (2021). https://docs.google.com/forms/d/1TqRX7OV gL_1zDd7ptSLX6xw6K5MbB5jRsMIzBCOwV Bc/edit

Bakas, D., Kostis, P., \& Petrakis, P. (2020). Culture and labour productivity: An empirical investigation. Economic Modelling, 85, 233243.

https://doi.org/10.1016/j.econmod.2019.05. 020.

Baležentis, T., Li, T., \& Chen, X. (2020). Has agricultural labor restructuring improved agricultural labor productivity in China? A decomposition approach. Socio-Economic Planning Sciences, 100967. https://doi.org/10.1016/j.seps.2020.100967.

Battisti, M., Belloc, F., \& Del Gatto, M. (2020). Labor productivity and firm-level TFP with technology-specific production functions. Review of Economic Dynamics, 35, 283-300. https://doi.org/10.1016/j.red.2019.07.003.

Bolis, I., Morioka, S.N., Leite, W.K.d.S., \& Zambroni-de-Souza, P.C. (2021). Sustainability Is All about Values: The Challenges of Considering Moral and Benefit Values in Business Model Decisions. 
Sustainability, 13, 664. https://doi.org/10.3390/su13020664.

Börsch-Supan, A., Hunkler, C., \& Weiss, M. (2021). Big data at work: Age and labor productivity in the service sector. The Journal of the Economics of Ageing, 19, 100319.

https://doi.org/10.1016/j.jeoa.2021.100319.

Deming, J., Kinsella, J., O'Brien, B., \& Shalloo, L. (2019). An examination of the effects of labor efficiency on the profitability of grassbased, seasonal-calving dairy farms. Journal of Dairy Science, 102, 9, 8431-8440. https://doi.org/10.3168/jds.2018-15299.

FAOLEX. (2014). State Programme on socioeconomic development of regions of the Republic of Azerbaijan for 2014-2018 years. http://www.fao.org/faolex/results/details/en /c/LEX-FAOC162071/

Florez, L., \& Cortissoz, J.C. (2017). Using Workers Compatibility to Predict Labor Productivity through Cluster Analysis. Procedia Engineering, 196, 359-365. https://doi.org/10.1016/j.proeng.2017.07.21 1.

Food provision as a factor in Azerbaijan's national security. (2015). Trend. https://www.trend.az/business/economy/34 22324.html

Gulaliyev, M. G., Abasova, S. T., Samedova, E. R., Hamidova, L. A., Valiyeva, S. I. \& Serttash, L. R. (2019). Assessment of agricultural sustainability (Azerbaijan case). Bulgarian Journal of Agricultural Science, 25(Suppl. 2), 80-89

International Trade Administration. (2020). Azerbaijan - Country Commercial Guide. https://www.trade.gov/countrycommercial-guides/azerbaijan-agriculture.

Inwood, S. (2017). Agriculture, health insurance, human capital and economic development at the rural-urban-interface. Journal of Rural Studies, 54, 1-14. https://doi.org/10.1016/j.jrurstud.2017.05.0 09.

Ismayilzade, A. A., Guliyeva, S., Teymurova, V., Azizova, R., \& Alishova, C. (2021). The impact of Covid-19 on the quality of human capital for the economic development of Azerbaijan. Journal of Eastern European and
Central Asian Research, 8(1), 26-39. https://doi.org/10.15549/jeecar.v8i1.639.

Jaouani, A., Nikolovska, M., Milovanovitch, M., \& Nielsen, S. (2020). Policies for human capital development in Azerbaijan. An ETF Torino Process assessment. https://www.etf.europa.eu/en/publicationsand-resources/publications/trp-assessmentreports/azerbaijan2020 ? page $=4 \&$ pid $=c 198$ e0 $c 1-d 05 a-4315-$ a572-03af8b32ba59.

Joseph, S. (2019). Why we need a more humanistic positive organizational scholarship: Carl Rogers' person-centered approach as a challenge to neoliberalism. The Humanistic Psychologist, 48. https://doi.org/10.1037/hum0000151.

Kudláč, Š., Štefancová, V., \& Majerčák, J. (2017). Using the Saaty Method and the FMEA Method for Evaluation of Constraints in Logistics Chain. Procedia Engineering, 187, 749-755. https://doi.org/10.1016/j.proeng.2017.04.43 3.

Mazilescu, C.-A., Auzoult-Chagnault, L., Viscu, L.I., \& Gangloff, B. (2021). Student Perception of the Social Value of Responsible Management. Societies, 11, 16. https://doi.org/10.3390/soc11010016.

Megits, N., Neskorodieva, I., \& Schuster, J. (2020). Impact assessment of the COVID19 on trade between Eastern Europe and China. Journal of Eastern European and Central Asian Research, 73), 385-399. https://doi.org/10.15549/jeecar.v7i3.579.

Menke, W. (2018). Factor Analysis. Geophysical Data Analysis (Fourth Edition). New York: Academic Press, 207-222.

Nedelko, Z., \& Potocan, V. (2021). Sustainability of Organizations: The Contribution of Personal Values to Democratic Leadership Behavior Focused on the Sustainability of Organizations. Sustainability, 13, 4207. https://doi.org/10.3390/su13084207.

Onegina, V., Megits, N., Antoshchenkova, V., \& Boblovskyi, O. (2020). Outcome of capital investment on labor productivity in agriculture sector of Ukraine. Journal of Eastern European and Central Asian Research, 71$), 12-25$. 
https://doi.org/10.15549/jeecar.v7i1.355

Rickaby, M.A., Glass, J., \& Fernie, S. (2020). Conceptualizing the Relationship between Personal Values and Sustainability - A TMO Case Study. Administrative Sciences, 10(1),15.

https://doi.org/10.3390/admsci10010015.

Saaty, T., \& Vargas, L. (2012). The possibility of group choice: Pairwise comparisons and merging functions. Social Choice and Welfare, 38(3), 481-496.

Sortheix, F.M., \& Schwartz, S.H. (2017). Values that Underlie and Undermine Well-Being: Variability across Countries. European Journal of Personality, 31(2), 187-201. https://doi.org/10.1002/per.2096.

Szybowski, J., Kułakowski, K., \& Prusak, A. (2020). New inconsistency indicators for incomplete pairwise comparisons matrices. Mathematical Social Sciences, 108, 138-145. https://doi.org/10.1016/j.mathsocsci.2020.0 5.002 .

The State Statistical Committee of the Republic of Azerbaijan. (2021). Retrieved April 28, 2021, from https://www.stat.gov.az/source/system_nat _accounts/?lang=en

Van Berkum, S. (2017). Market and competitiveness analysis of the Azerbaijan agricultural sector: an overview. https://edepot.wur.nl/450210.

Wagner, D. (2020). Augmented HumanCentered Management. Human Resource Development for highly automated business environments, XXiii, 13-27.

Wang, Y., \& Zhao, G. (2019). Life cycle assessment of potential pollutant-induced human capital loss caused by different agricultural production systems in Beijing, China. Journal of Cleaner Production, 240, 118141. https://doi.org/10.1016/j.jclepro.2019.11814 1.

\section{CORRESPONDING AUTHOR:}

Shafa Guliyeva, email: shafa_guliyeva@unec.edu.az 